\title{
Choose your (international) contacts wisely: A multilevel analysis on the impact of intergroup contact while living abroad ${ }^{\text {is }}$
}

\author{
Nicolas Geeraert ${ }^{\mathrm{a}, *}$, Stéphanie Demoulin ${ }^{\mathrm{b}}$, Kali A. Demes ${ }^{\mathrm{a}}$ \\ a University of Essex, United Kingdom

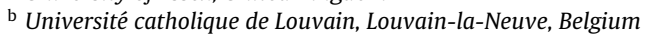

\section{A R T I C L E I N F O}

\section{Article history:}

Received 11 December 2012

Received in revised form 1 August 2013

Accepted 5 August 2013

\section{Keywords:}

Sojourn

Contact

Stress

Cultural adjustment

Intergroup behaviour

\begin{abstract}
A B S T R A C T
A two year longitudinal study examined the influence of social contact abroad on student sojourners' cultural adjustment and intergroup affect. Social contact was measured with regard to the three people that sojourners (exchange students) spent most time with. Both the quality of the relationship with each contact and the cultural background (host national, co-national) of each contact were measured, that is contact quality and contact source, respectively. The data were analysed through repeated measures multilevel modelling. Results indicate that good quality contact (independent of source) is associated with higher cultural adjustment in sojourners and lower levels of stress. Contact quality however, was not associated with intergroup affect. Source of contact was found to matter, especially over time. Specifically, in the later stages of the sojourn, having more co-national contacts among ones three most frequent contacts, was associated with higher levels of stress, reduced cultural adjustment and higher secondary outgroup derogation. These findings suggest that who sojourners have contact with, matters for both cultural adjustment and intergroup affect.
\end{abstract}

(c) 2013 Elsevier Ltd. All rights reserved.

In today's global village, intercultural contact is rapidly increasing in frequency. UN estimates of the last 25 years show an increase in the number of migrants from 111 million in 1985 to 214 million in 2010, an increase of 93\% (UN, 2009). The growth in student mobility is even more dramatic. Over a 10 year period, the number of students studying abroad grew from 1.78 million in 2000 to 3.18 million in 2010, an increase of nearly 80\% (UNESCO, 2013). Unsurprisingly then, international students are among the most studied sojourner populations in acculturation research (Bochner, 2006). While research on international students is often focussed on university students (Cemalcilar \& Falbo, 2008; Fritz, Chin, \& DeMarinis, 2008),

\footnotetext{
is This research was supported by British Academy [grant number SG-46171]. Data from this project has previously been presented in “Geeraert, N., \& Demoulin, S. (in press). Acculturative stress or resilience? A longitudinal multilevel analysis of sojourners' stress and self-esteem. Journal of Cross-Cultural Psychology. doi:10.1177/0022022113478656.

* Corresponding author at: Department of Psychology, University of Essex, Wivenhoe Park, Colchester CO4 3SQ, United Kingdom. Tel.: +44 1206873810; fax: +441206873801 .

E-mail address: geeraert@essex.ac.uk (N. Geeraert).
} 
exchange students are also an interesting, yet less examined, group (Geeraert \& Demoulin, 2013; Ward \& Kennedy, 1993, 1996) $)^{1}$.

Intercultural contact has been extensively researched in terms of its role in cultural adaptation and well-being (Berry, 2006; Smith \& Khawaja, 2011; Ward, Bochner, \& Furnham, 2001) and also in intergroup behaviour (Pettigrew \& Tropp, 2006). Importantly, the effect that intercultural contact has on these outcomes has been shown to vary according to the nature of contact. Specifically, contact varies in two distinct ways (Brown \& Hewstone, 2005), in terms of contact quality (positive versus negative interactions) and contact source (cultural background of contacts).

The present study is a longitudinal examination of the impact of contact quality and contact source on intercultural exchange students' cultural adjustment, well-being and intergroup affect. In this study, contact quality and source are in relation to the three contacts with whom sojourners spend most time; these will be called close contacts. While the relationships between intercultural contact and cultural adjustment and between intercultural contact and intergroup affect have been studied previously, the current research can contribute in three ways. First, cultural adjustment and intergroup affect are typically assessed independently (e.g., Turner, Hewstone, \& Voci, 2007; Yoon, Lee, \& Goh, 2008). In this study, data on both cultural adjustment and intergroup affect are collected from a single sample of student sojourners. Second, acculturation research, still relying heavily on cross-sectional designs, can benefit from longitudinal research. Finally, there is still uncertainty in the literature about the different roles that contact quality and contact source play in sojourners' adjustment and intergroup behaviour. This study will contribute new insights on these relationships.

\section{1.}

\subsection{Intercultural contact}

Moving into a new cultural environment can be both challenging and exciting. Sojourners will come into contact with people from various cultural groups, including nationals from the host country (host nationals), home country (co-nationals), and from countries other than these (other nationals; e.g., other sojourners). This social contact will be one of the driving influences of adjustment to the host environment (Cohen \& Wills, 1985) and perceptions of different cultural groups (Allport, 1954). In addition, given the hierarchical nature of social networks (Zhou, Sornette, Hill, \& Dunbar, 2005), it is important to consider the closeness of contacts. Specifically, a close contact group of three to five individuals is believed to be particularly influential in the provision of social support (Dunbar \& Spoor, 1995). A sojourner travelling solo, however, does not have direct access to their close contact group and must become acquainted with an entirely new set of contacts. Thus, it is likely that the novel contacts that sojourners make, specifically those with whom they spend the most time, will be influential to their cultural adjustment and intergroup affect.

\subsection{Cultural adjustment and stress}

Intercultural sojourning can be a challenging experience; novel cultural situations may challenge even the most basic of daily routines, and thus require adaptation and learning on many levels. Naturally, the rather intense process of cultural adjustment can lead to phases of psychological strain, known as acculturative stress (Berry, 2006). Indeed, a number of studies show that the initial period upon entry to a new country is marked by an increase in psychological stress for university students (Brown \& Holloway, 2008; Nash, 1991), and exchange students (Ward \& Kennedy, 1996).

Social contact is a key factor in dealing with cultural adjustment and stress (Berry, 2006; Smith \& Khawaja, 2011; Ward et al., 2001). For instance, studies of Chinese university students in the US have demonstrated the impact of social contact or support on cultural adjustment (Wang, Heppner, Fu, Zhao, Li, \& Chuang, 2012; Zhang \& Goodson, 2011). In addition, contact with host nationals has been associated with lower levels of acculturative stress, and higher levels of well-being and adjustment in both student and migrant samples (Furnham \& Li, 1993; Kashima \& Loh, 2006; Searle \& Ward, 1990). Other researchers have argued that host national contact is even a pre-requisite for cultural adjustment (Berry, Kim, Minde, \& Mok, 1987).

The influence of contact with fellow co-nationals on the other hand is less clear. Some researchers have argued that conational contact abroad creates a safe protective bubble supporting the sojourner (Adelman, 1988; Church, 1982), providing learning opportunities through discussion (Woolf, 2007). It has been argued that co-nationals may be the most supportive contact group for student sojourners (Sykes \& Eden, 1987), leading to increased adjustment (Ward \& Kennedy, 1993a,b) and lower acculturative stress (Berry et al., 1987). Others however, claim that extensive contact with co-nationals can have negative consequences for international students, including poorer adjustment and lower levels of satisfaction abroad (Adelman, 1988; Hendrickson, Rosen, \& Aune, 2011). Interestingly, Neri and Ville (2008) found that while co-national contact was associated with lower academic success, it was related to increased well-being abroad. Thus, studies have produced somewhat mixed or conflicting results on the impact of the co-national bubble.

\footnotetext{
1 Exchange students differ from international university students in a number of ways. Compared to university students, exchange students tend to be somewhat younger, often still attending high school, will often live with a local host family (instead of university residences), and may be primarily motivated by the cultural experience (as opposed to obtaining an academic degree).
} 
Table 1

Sojourners' different destinations broken down by continent, for each continent is shown the countries IOC codes, number of countries, the number and percentage of sojourners for that destination.

\begin{tabular}{|c|c|c|c|c|}
\hline Destination & Countries & $N$ countries & $N$ sojourners & Percentage \\
\hline Latin America & ARG, BOL, BRA, CRC, DOM, ECU, GUA, HON, MEX, PAN, PAR, PER & 12 & 89 & $54.4 \%$ \\
\hline North America & USA & 1 & 26 & $16.3 \%$ \\
\hline Europe & FIN, HUN, ISL, ITA, LAT, NOR, TUR & 7 & 21 & $13.1 \%$ \\
\hline Asia & INA, MAS, PHI, THA & 4 & 14 & $8.8 \%$ \\
\hline Africa & GHA, RSA, TUN & 3 & 6 & $3.8 \%$ \\
\hline Australasia & AUS, NZL & 2 & 6 & $3.8 \%$ \\
\hline Total & & 29 & 162 & $100.0 \%$ \\
\hline
\end{tabular}

We argue that these discrepancies may be explained, in part, by a temporal perspective. Specifically, whether co-national contact is adaptive or maladaptive may vary according to the particular stage of the sojourn. Initially, on arrival to the host country when stress is argued to be at its highest (Ward et al., 2001), close contact with co-nationals may be very welcome and have the effect of reducing stress and providing a sense of adjustment. Over time however, as the sojourner becomes more settled and comfortable in the new society, extensive contact with co-nationals may be at the detriment of cultural learning and adjustment. Given this reasoning, good quality close contact at the start of a sojourn, be it from co-nationals, host nationals, or others, should have a positive effect on sojourners adjustment. Over time however, we would argue that source of contact matters more. Close host national contacts should facilitate adjustment while too much co-national contact may hold students back.

\subsection{Intergroup affect}

Social Identity Theory (Tajfel, 1974; Tajfel \& Turner, 1986) suggests that mere categorization within a group is sufficient to create an identity to that group and thus trigger intergroup biases, such as ingroup favouritism and outgroup derogation (Hogg, 2003; Moscatelli \& Rubini, 2011). In the sojourning context, one would expect extensive contact with co-nationals to reinforce the ingroup identity, fostering intergroup biases. Host nationals however, although an outgroup, may in fact not be perceived that way. Exchange students, typically motivated to learn about their host society (Richmond, 1993), are likely to identify to some extent with their host culture and consequently not direct negative biases towards them.

The contact hypothesis (Allport, 1954; Pettigrew \& Tropp, 2006) suggests that meaningful and positive contact between members of different groups will lead to a reduction of prejudice and negative feelings between those groups (Pettigrew, 1998). Close contact by sojourners with host nationals is therefore expected to foster more positive affect towards them. Less clear however, would be the impact of this intergroup contact on feelings towards secondary outgroups, not involved in the contact (Pettigrew \& Tropp, 2000), that is whether contact with one outgroup leads to positive changes in perceptions towards other related but non-contacted outgroups. While a number of studies have found evidence for this secondary transfer effect in non-relocating samples (Bowman \& Griffin, 2012; Pettigrew, 2009; Tausch et al., 2010), few studies have examined this effect in a sojourning context. However, Stangor, Jonas, Stroebe, and Hewstone, (1996), in a sample of exchange students, did not find a transfer of positive affect from the hosting cultural group to a control cultural group.

Based on Social Identity Theory and the contact hypothesis, extensive co-national contact would be expected to have a positive impact on sojourners' feelings towards the ingroup (ingroup favouritism) and a negative impact on secondary (not the host) outgroups (outgroup derogation). More close host national contact however is expected to foster positive feelings towards host nationals (basic contact hypothesis) and possibly also towards other outgroups (secondary transfer effect).

\subsection{The present study}

This study seeks to examine the impact of the quality and source of close contacts (Dunbar \& Spoor, 1995) while abroad, on cultural adjustment, stress and the intergroup affect of intercultural exchange students. Students were followed for 2 years, over four different time points: pre-sojourn ( $t 1)$, at the start of the sojourn ( $t 2)$, at the end of the sojourn ( $t 3)$, and 1 year post-sojourn ( $t 4)$. All students were Belgian residents, participating in a one year exchange programme (2005-2006 with AFS Belgium Flanders), travelling from Belgium to 1 of 29 different host destinations (see Table 1).

Intercultural exchanges such as these are loosely based on the contact hypothesis through cultural submersion. Students are typically placed in a host family, and enrol at a local high school or project placement. Intercultural contact is a primary focus of such exchange programmes and participants are actively discouraged to have extensive or frequent contact with co-nationals. Focusing on who students are having close contact with, is therefore particularly relevant in this context.

\subsection{Hypotheses}

In terms of stress and adjustment as outcomes, we expect that average contact quality across close contact (independent of source) will be related to lower stress and greater adjustment - particularly in the early phases of a sojourn. Over time 
source of contact is expected to matter. Specifically, having more co-nationals as close contacts is expected to be associated with lower levels of adjustment and higher levels of stress.

In line with the contact hypothesis, we predict that having more host nationals as close contacts during the sojourn will have a positive impact on affect towards host nationals as well as towards other outgroups (secondary transfer effect). The number of co-national close contacts that one has, is expected to be associated with positive affect towards co-nationals (ingroup favouritism) and negative affect towards other outgroups (secondary outgroup derogation). We do not expect overall contact quality to influence affect ratings towards particular cultural groups as the contact quality ratings are at the level of very specific individuals, whereas intergroup affect ratings are assessed at the group level.

\section{Method}

\subsection{Design}

Data was collected from intercultural exchange students over a 24 month period at 4 time points ( $t 1$ vs. $t 2$ vs. $t 3$ vs. t4). The first survey was distributed a few months prior to the start of the sojourn (June, 2005). The next two surveys were recorded about 6 weeks into the sojourn (October-November, 2005) and towards the end of the sojourn (May, 2006). Finally, all participants were contacted one last time, approximately one year after their return home (May-June, 2007).

\subsection{Participants}

Exchange students were approached at a national meeting of AFS Belgium Flanders prior to their departure abroad. Participants who successfully completed each survey were entered into a prize draw offering one of 6 travel vouchers $(500-250 €)$. A total of 162 sojourners participated in the study $\left(M_{\mathrm{age}}=17.9\right.$ years, $30 \%$ male). All students were Belgian residents. Ethnic background was not recorded directly, but typically most participants on this programme are white Flemish. Interestingly, $94 \%$ of exchange students had not previously travelled to their host country.

\subsection{Measures and procedure}

At each data wave, participants were sent an e-mail inviting them to complete an online survey. The measures, presented in Dutch, were embedded within a questionnaire containing a larger series of questions. Below is a description of the relevant measures, specifying the times at which they were recorded:

\subsubsection{Demographics}

At $t 1$ participants answered some questions regarding their age, gender, and education.

\subsubsection{Close contact measure}

During the sojourn ( $t 2$ and $t 3$ ), participants reported on the three individuals they had most contact with (Stangor, Jonas, Stroebe, \& Hewstone, 1996). Thus, rather than examining contact on a broader level (e.g. Brown, Vivian, \& Hewstone, 1999; Islam \& Hewstone, 1993), this measure gauges the degree of intergroup exposure at the level of sojourners' closest contacts. ${ }^{2}$ Specifically, participants answered the following question "Think about 3 people with whom you have spent the most time. For each person, give their initials, their nationality, and how good your relationship is with them." For each close contact, participants rated the quality of their relationship on a scale from 1 (not very good) to 7 (very good).

A key question in this paper is whether average contact quality, across the three closest contacts, is associated with wellbeing. Thus, an overall contact quality score was created. Specifically, the quality ratings across the three named contacts were averaged, resulting in a single score ranging from 1 to 7 , with higher scores indicating good quality contact.

To establish how many of the close contacts, per participant, belonged to the host national or co-national group, we obtained a count of how many contacts were listed with each nationality. These count scores ranged from 0 to 3 . In general, participants more frequently listed host nationals as close contacts than either co-nationals or other nationals. However, there was also substantial variability in participants' responses. Specifically, some participants reported all three of their close contacts to come from one and the same group, and this occurred for all sources of contact (host, co-, and other nationals).

\subsubsection{Cultural adjustment}

During the sojourn ( $t 2$ and $t 3$ ), participants indicated the extent to which they felt comfortable and adjusted to the host society. We constructed a 5 item scale to measure this construct (e.g., "I feel well adapted to my new environment" and "I think that I will never adjust to this new environment"). Items were rated on a 7-point scale ( 1 =strongly disagree,

\footnotetext{
2 The nature of this measure is such that sojourners will not necessarily have close contacts from each group, which will reflect reality. Indeed, whereas some sojourners may submerge themselves in the host culture by having contact primarily or only with host nationals, other sojourners may have more contact with other sojourners or co-nationals, with little or no close host national contact.
} 
7 strongly agree $)$. Following good reliability $\left(\alpha_{t 2}=.80, \alpha_{t 3}=.82\right)$, a scale was computed for which higher scores represent higher adjustment.

\subsubsection{Stress}

Throughout the study ( $t 1$ to $t 4$ ), participants completed a Dutch version (Smolderen, Vingerhoets, Croon, \& Denollet, 2007) of the Perceived Stress Scale (Cohen, Kamarck, \& Mermelstein, 1983). This scale consists of 14 statements rated on a 7 -point scale $(1=$ never, $7=$ frequently $)$ that assess the level of stress experienced during the past month. Internal consistency for the scale at each timewave was good $\left(\alpha_{t 1}=.81, \alpha_{t 2}=.84, \alpha_{t 3}=.87, \alpha_{t 4}=.90\right)$. Higher scores on this scale represent higher stress.

\subsubsection{Intergroup affect}

Intergroup affect was assessed at each data wave ( $t 1$ to $t 4$ ) by presenting participants with a 'feeling thermometer' (Haddock, Zanna, \& Esses, 1993), which asked them to indicate how warm or cold they felt towards different cultural groups on a scale from $0^{\circ}$ (cold/negative) to $100^{\circ}$ (warm/positive). Participants rated affect towards host nationals, co-nationals (Belgians), and two secondary outgroups, Dutch and Moroccans. These two outgroups were chosen because each are a migrant population in Belgium Flanders and therefore would be salient to the sojourner sample. Whereas perception of the Dutch is somewhat ambivalent (Aspeslagh et al., 2000), Moroccans are perceived more negatively (Billiet \& Swyngedouw, 2009). Importantly, none of the 27 potential host countries featured the Netherlands or Morocco.

\subsubsection{Evaluation measure}

One year after having returned home (t4), participants were asked to evaluate their sojourn, by indicating the extent to which their experience had been pleasant, difficult, easy, enriching, important, negative, and positive on a scale from 1 (not $a$ lot) to 7 (a lot). Following satisfactory reliability $(\alpha=.70)$, the 7 items were averaged such that higher scores represent a more positive evaluation.

\section{Results}

A total of 162 sojourners completed the survey at $t 1$. In terms of attrition, $87 \%$ of participants $(N=139)$ finished more than one timewave and $62 \%(N=100)$ completed all timewaves. Importantly, attrition was not statistically different across age, gender, or educational level (all p's >.10), nor was there any difference in attrition for measures of adjustment, stress, affect or close contact (all $F \mathrm{~s}<1$ ).

\subsection{Analysis strategy}

Repeated measures multilevel modelling (MLM) was used for the main analyses (Hox, 2010). ${ }^{3}$ Specifically, we analysed the survey data with completed timewaves as the primary level of analysis, and individuals at the higher level. Repeated measures MLM provides us with two clear advantages. First, all completed timewaves can be included in the analyses, regardless of whether participants completed the study. In other words, attrition is less of a problem in repeated measures MLM. Second, MLM makes it easy to explore how variables influence one another over time. For instance, we can investigate how contact covaries with cultural adjustment independent of time (by looking at $t 2$ and $t 3$ simultaneously). Further, we can examine whether the effect of contact on cultural adjustment changes over time (by looking at the interaction of time by contact). In short, MLM is an ideal technique for analysing longitudinal data.

The MLM analyses in this project included data from $t 2$ to $t 4$ (recoded 0 to 2 ), with $t 1$ data included as an invariant baseline (for stress and affect). The variables for contact quality and source were recorded at $t 2$ and $t 3$. For analyses involving $t 4$, contact scores were imputed from $t 3$. Finally, the data were prepared by $z$-scoring all variables. In the resulting dataset the primary unit of analysis (level 1$)$ was completed timewaves $(N=351)$, with individuals at level $2(N=139)$. All multilevel analyses were conducted with MLwiN 2.1 (Rasbash, Charlton, Browne, Healy, \& Cameron, 2009).

\subsection{Close contact explaining cultural adjustment}

The role of contact quality and source (at $t 2$ and $t 3$ ) in predicting cultural adjustment (at $t 2$ and $t 3$ ) was examined through a series of multilevel models (see Table 2). The null model (Model 1) made it possible to calculate the intraclass correlation, showing that $34 \%$ of the variance was at the individual level (level 2 ), and $66 \%$ at the repeated measures level (level 1 ). The addition of time as a predictor of adjustment (Model 2) statistically improved the model, $\chi^{2}(1)=6.23, p<.05$. The effect of time indicates that participants were more adjusted at the end of the sojourn $(t 3)$ than at the beginning $(t 2)$. Next, we added

\footnotetext{
${ }^{3}$ Conceptually similar to regression, MLM is well-suited for nested designs where the data structure is hierarchical, as MLM allows analysing the data at conceptually different levels. A typical example from educational research consists of students nested within schools. This data could be examined both at the primary level (i.e. students) and at the higher contextual level (i.e. schools). Repeated measures MLM is a special case; in which observations are nested within participants.
} 
Table 2

Multilevel analysis for adjustment over time ( $t 2$ to $t 3$ ) by quality and source of close contacts during the exchange.

\begin{tabular}{|c|c|c|c|c|c|c|c|c|c|c|c|c|}
\hline & \multicolumn{3}{|c|}{ Model 1 (null model) } & \multicolumn{3}{|c|}{ Model 2 (+time) } & \multicolumn{3}{|c|}{ Model 3 (+contact) } & \multicolumn{3}{|c|}{ Model 4 (+interaction) } \\
\hline & $\beta$ & $S E$ & $p$ & $\beta$ & $S E$ & $p$ & $\beta$ & $S E$ & $p$ & $\beta$ & $S E$ & $p$ \\
\hline Intercept & -.03 & .08 & .37 & -.14 & .09 & .06 & -2.70 & .54 & $<.001$ & -3.99 & .74 & $<.001$ \\
\hline \multicolumn{13}{|l|}{ Repeated measures effects } \\
\hline Time & & & & .28 & .11 & $<.01$ & .14 & .11 & .10 & 2.45 & .97 & $<.01$ \\
\hline \multicolumn{13}{|l|}{ Time variant covariates } \\
\hline Quality of close contact & & & & & & & .39 & .08 & $<.001$ & .62 & .12 & $<.001$ \\
\hline$N$ of host national close contacts & & & & & & & .16 & .09 & .04 & .10 & .11 & .19 \\
\hline$N$ of co-national close contacts & & & & & & & -.06 & .13 & .32 & .04 & .14 & .40 \\
\hline \multicolumn{13}{|l|}{ Interactions } \\
\hline Time $\times$ quality of close contact & & & & & & & & & & -.41 & .15 & $<.01$ \\
\hline Time $\times N$ of host national contacts & & & & & & & & & & .15 & .14 & .15 \\
\hline Time $\times N$ of co-national contacts & & & & & & & & & & .56 & .22 & $<.01$ \\
\hline \multicolumn{13}{|l|}{ Residual variance } \\
\hline Repeated measures level $\left(\sigma^{2}{ }_{e}\right)$ & .67 & .10 & $<.001$ & .63 & .09 & $<.001$ & .57 & .08 & $<.001$ & .51 & .07 & $<.001$ \\
\hline Within-participants level $\left(\sigma^{2}{ }_{u}\right)$ & .35 & .11 & $<.001$ & .37 & .11 & $<.001$ & .32 & .09 & $<.001$ & .34 & .09 & $<.001$ \\
\hline Deviance (df) & \multicolumn{3}{|c|}{$655.0(3)$} & \multicolumn{3}{|c|}{$648.8(4)$} & \multicolumn{3}{|c|}{$621.0(7)$} & \multicolumn{3}{|c|}{$604.9(10)$} \\
\hline
\end{tabular}

the 3 close contact variables, contact quality, number of host national contacts and number of co-national contacts (Model 3 ), improving the model significantly, $\chi^{2}(3)=27.80, p<.001$. Whilst controlling for time, both quality of contact and more close contact with host nationals were positively and significantly associated with greater adjustment.

The inclusion of interactions between time and contact variables (Model 4) significantly improved the model fit, $\chi^{2}(3)=16.08, p<.001$. Two main effects emerged. As before, an effect of time suggested sojourners were more adjusted at $t 3$ compared to $t 2$. Also, quality of contact was again positively associated with adjustment. These main effects were qualified by two interactions. First, an interaction of time by quality of contact revealed that the association between quality of close contact and adjustment was stronger in the beginning of the sojourn $\left(\beta_{t 2}=.40, p<.001\right)$ than at the end $\left(\beta_{t 3}=.21, p=.03\right)$. Secondly, an interaction of time by number of co-national close contacts indicated that, although number of co-nationals was not associated with adjustment at the start $\left(\beta_{t 2}=.00\right)$, a negative association emerged at the end of the sojourn $\left(\beta_{t 3}=-.22\right.$, $p=.03$ ); having more co-nationals among close contacts was associated with less adjustment.

The previous analyses revealed an overall effect of quality of contact. It is conceivable that the effect of quality varies by contact nationality. To examine this possibility, a follow-up analysis was conducted on those timewaves for which participants reported both host nationals and co-nationals among their contacts $(N=86)$. Specifically, quality scores by nationality were added to a basic model containing overall quality of contact. Crucially, the addition of quality by nationality, did not improve the fit of the basic model, $\chi^{2}(2)=1.00, p=.61$.

\subsection{Close contact explaining stress}

Stress during the sojourn (at $t 2$ and $t 3$ ) was examined through a similar series of multilevel models (see Table 3 ). Compared to the analyses on adjustment, the analyses on stress revealed a pattern that was roughly reversed, conceptually replicating the previous findings. The intraclass correlation (Model 1 ) indicated that $51 \%$ and $49 \%$ of the variance was at the individual or repeated measures level respectively. Next, both time and baseline stress were added to the model (Model 2), significantly

Table 3

Multilevel analysis for stress over time ( $t 2$ to $t 3$ ) by quality and source of close contacts during the exchange.

\begin{tabular}{|c|c|c|c|c|c|c|c|c|c|c|c|c|}
\hline & \multicolumn{3}{|c|}{ Model 1 (null model) } & \multicolumn{3}{|c|}{ Model 2 (+time) } & \multicolumn{3}{|c|}{ Model 3 (+contact) } & \multicolumn{3}{|c|}{ Model 4 (+interaction) } \\
\hline & $B$ & SE & $p$ & $\beta$ & SE & $p$ & $\beta$ & SE & $p$ & $\beta$ & $S E$ & $p$ \\
\hline Intercept & -.06 & .08 & .21 & -.11 & .08 & .09 & .55 & .43 & .10 & 1.24 & .61 & .02 \\
\hline \multicolumn{13}{|l|}{ Repeated measures effects } \\
\hline Time & & & & -.04 & .10 & .34 & .02 & .10 & .44 & -1.22 & .78 & .06 \\
\hline Baseline stress $(t 1)$ & & & & .33 & .08 & $<.001$ & .33 & .08 & $<.001$ & .34 & .08 & $<.001$ \\
\hline \multicolumn{13}{|l|}{ Time variant covariates } \\
\hline Quality of close contact & & & & & & & -.14 & .06 & .01 & -.23 & .09 & $<.01$ \\
\hline$N$ of host national close contacts & & & & & & & .05 & .09 & .29 & -.02 & .11 & .44 \\
\hline$N$ of co-national close contacts & & & & & & & .13 & .12 & .15 & .02 & .14 & .45 \\
\hline \multicolumn{13}{|l|}{ Interactions } \\
\hline Time $\times$ quality of close contact & & & & & & & & & & .15 & .12 & .09 \\
\hline Time $\times N$ of host national contacts & & & & & & & & & & .11 & .14 & .22 \\
\hline Time $\times N$ of co-national contacts & & & & & & & & & & .37 & .22 & $<.05$ \\
\hline \multicolumn{13}{|l|}{ Residual variance } \\
\hline Repeated measures level $\left(\sigma^{2}{ }_{e}\right)$ & .49 & .07 & $<.001$ & .48 & .07 & $<.001$ & .49 & .07 & $<.001$ & .48 & .07 & $<.001$ \\
\hline Within-participants level $\left(\sigma^{2}{ }_{u}\right)$ & .52 & .11 & $<.001$ & .44 & .10 & $<.001$ & .39 & .09 & $<.001$ & .39 & .09 & $<.001$ \\
\hline Deviance (df) & \multicolumn{3}{|c|}{$640.3(3)$} & \multicolumn{3}{|c|}{$624.5(5)$} & \multicolumn{3}{|c|}{$618.0(8)$} & \multicolumn{3}{|c|}{$613.8(11)$} \\
\hline
\end{tabular}


Table 4

Final models of multilevel analysis for intergroup affect over time ( $t 2-t 4)$ by quality and source of close contacts during the exchange.

\begin{tabular}{|c|c|c|c|c|c|c|c|c|c|c|c|c|}
\hline & \multicolumn{12}{|c|}{ Affect towards } \\
\hline & \multicolumn{3}{|c|}{ Host nationals } & \multicolumn{3}{|c|}{ Belgian ingroup } & \multicolumn{3}{|c|}{ Dutch outgroup } & \multicolumn{3}{|c|}{ Moroccan outgroup } \\
\hline & $\beta$ & $S E$ & $p$ & $\beta$ & $S E$ & $p$ & $\beta$ & $S E$ & $p$ & $\beta$ & $S E$ & $p$ \\
\hline Intercept & -1.10 & .41 & $<.01$ & .30 & .35 & .20 & .68 & .36 & .03 & .45 & .33 & .09 \\
\hline \multicolumn{13}{|l|}{ Repeated measures effects } \\
\hline Time & .04 & .06 & .27 & -.16 & .05 & $<.001$ & .02 & .05 & .36 & .02 & .05 & .30 \\
\hline Baseline affect $(t 1)$ & .21 & .07 & $<.01$ & .39 & .05 & $<.001$ & .48 & .06 & $<.001$ & .53 & .05 & $<.001$ \\
\hline \multicolumn{13}{|l|}{ Time variant covariates } \\
\hline Quality of close contact & .06 & .06 & .17 & -.03 & .05 & .27 & -.05 & .05 & .17 & -.04 & .05 & .21 \\
\hline$N$ of host national close contacts & .33 & .08 & $<.001$ & .08 & .07 & .14 & -.11 & .08 & .07 & -.05 & .07 & .23 \\
\hline$N$ of co-national close contacts & .10 & .11 & .18 & .09 & .10 & .19 & -.22 & .11 & .02 & -.18 & .09 & .03 \\
\hline \multicolumn{13}{|l|}{ Residual variance } \\
\hline Repeated measures level $\left(\sigma^{2}{ }_{e}\right)$ & .79 & .08 & $<.001$ & .58 & .06 & $<.001$ & .57 & .06 & $<.001$ & .49 & .05 & $<.001$ \\
\hline Within-participants level $\left(\sigma_{u}^{2}\right)$ & .20 & .07 & $<.01$ & .17 & .05 & $<.001$ & .23 & .06 & $<.001$ & .17 & .05 & $<.001$ \\
\hline Deviance (df) & \multicolumn{3}{|c|}{$981.8(8)$} & \multicolumn{3}{|c|}{$880.1(8)$} & \multicolumn{3}{|c|}{$895.4(8)$} & \multicolumn{3}{|c|}{$828.8(8)$} \\
\hline
\end{tabular}

improving the fit, $\chi^{2}(2)=15.82, p<.001$. Baseline stress was a significant predictor of stress during the sojourn, but time was not. Overall, the addition of the close contact variables (Model 3) did not significantly improve the model, $\chi^{2}(3)=6.50$, $p=.09$. Nevertheless, quality of close contact was shown to be significant, such that higher quality of contact was related to lower levels of stress.

The inclusion of interactions between time and close contact variables (Model 4) did not improve the overall fit of the model, $\chi^{2}(3)=4.19, p=.24$. However, at the level of individual predictors, the quality of contact effect persisted. In addition, an interaction of time by number of co-national close contacts emerged, suggesting the association between co-national close contacts and stress changed over time. Follow-up tests revealed there to be no association between number of conational contacts and stress at the start of the sojourn $\left(\beta_{t 2}=.04\right)$, but a positive association emerged at the end of the sojourn $\left(\beta_{t 3}=.17\right)$, such that more co-national contact was associated with higher levels of stress.

A follow-up analysis was conducted to examine whether quality of contact by nationality played a role over and above overall quality. The results show that the addition of quality by nationality did not improve the fit, $\chi^{2}(2)=1.59, p=.45$.

\subsection{Close contact explaining intergroup affect}

To examine the association between close contact and intergroup affect (at $t 2, t 3$, and t4) a series of multilevel models was constructed. Four different models were created for affect towards each cultural group (host nationals, co-nationals, and two secondary outgroups). Each model was constructed in two steps. First, a null model of affect was created. Next, the three contact variables were added whilst controlling for time and baseline affect $(t 1)$. Final models are shown for each type of intergroup affect (Table 4).

\subsubsection{Affect towards host nationals}

The model of host national affect was superior over the null model, $\chi^{2}(5)=29.32, p<.001$. The analysis showed a significant positive effect of baseline affect but no effect of time. In terms of contact, number of host national close contacts was positively associated with affect towards host nationals, indicating the occurrence of the contact hypothesis. Neither quality of contact nor number of co-national close contacts contributed significantly to this model.

\subsubsection{Affect towards co-nationals}

The final model on co-national affect was better than the null model, $\chi^{2}(5)=58.45, p<.001$. A significant and positive effect of the baseline emerged, as well as a significant negative effect of time, such that controlling for all other variables, sojourners affect towards co-nationals became less positive over time. Importantly and contrary to our prediction, the number of co-national contacts was not associated with affect towards co-nationals. None of the other close contact variables were associated with co-national affect.

\subsubsection{Affect towards secondary outgroups}

Two separate multilevel analyses were conducted on affect towards the Dutch and Moroccan, two salient Belgian outgroups. For affect towards the Dutch, the final model was better than the null model, $\chi^{2}(5)=53.52, p<.001$. There was an effect of baseline affect, but no effect of time. However, the number of close co-national contacts was negatively related to affect towards the Dutch, indicating that the more contact sojourners had with other Belgians while abroad, the 
more negatively they felt towards the Dutch. Somewhat unexpectedly, the analysis suggested a negative relation between secondary outgroup affect and number of host national close contacts, although this effect failed to reach significance. ${ }^{4}$

For the Moroccan outgroup, a similar pattern emerged. The final model was better than the null model, $\chi^{2}(5)=84.02$, $p<.001$. Baseline affect was significant, but the effect of time was not. More importantly, a significant negative association between number of co-national contacts and Moroccan affect emerged, such that more co-national contact was related to less positive affect towards Moroccans.

These analyses support the prediction that contact with co-nationals will be associated with secondary outgroup derogation. However, host national contact was not significantly positively related to affect towards these outgroups, failing to provide evidence of a secondary transfer effect.

\subsubsection{Quality of contact by nationality}

Although none of the analyses on affect revealed an effect of quality of contact, it is possible that quality by nationality plays a role in predicting intergroup affect. To examine this possibility, an additional series of analyses was conducted. The addition of quality scores by nationality did not improve the model's fit for affect towards co-nationals, nor for the secondary outgroups (all $\chi^{2}$ s $<1$ ). However, quality by nationality did improve the model of affect towards host nationals, $\chi^{2}(2)=6.23$, $p<.05$. Specifically, the analysis revealed that quality of close contact with host nationals was associated with positive affect towards host nationals.

\subsection{Close contact explaining sojourn evaluation}

Finally, the role of close contacts on the post-sojourn evaluation (t4) was examined through multiple regression. Sojourn evaluation ( 1 year post exchange) was regressed on $t 3$ contact quality, number of host national and co-national contacts. The contact measures explained $15 \%$ of the variance in sojourn evaluation, $F(3,111)=6.67, p<.001$. Both contact quality $(\beta=.21$, $p=.02)$ and number of co-national contacts $(\beta=-.26, p<.01)$ were independent predictors, suggesting that better quality of contact during the sojourn is predictive of a more positive evaluation, but that having more co-nationals among close contacts is predictive of a poorer evaluation. There was no effect of number of host national close contacts $(\beta=.09, p=.36)$. A follow-up test examining quality by nationality did not improve the model $(\Delta F<1)$.

\section{Discussion}

A longitudinal study was conducted following a group of exchange students before, during, and after their sojourn. The study aimed to investigate the impact of close intercultural contact on cultural adjustment, stress and intergroup affect.

\subsection{Cultural adjustment and stress}

Predictions regarding the impact of quality and source of close contacts on cultural adjustment and stress took a temporal approach. The early phases of a sojourn can be the most challenging (Brown \& Holloway, 2008) and therefore good social contact, from any source, may provide an important support base (Cohen \& Wills, 1985). Our results show that average close contact quality was significantly related to higher levels of cultural adjustment and lower levels of stress, particularly at the beginning of the sojourn.

Regarding contact source, we predicted that who students had contact with, while not important at the start of the exchange, would have an impact at the later stages. Specifically, we argued that close contact with co-nationals would hinder cultural adjustment and enhance stress (Hendrickson et al., 2011). This is what we found. At the beginning of the sojourn, close contact with co-nationals was not related to adjustment nor stress. Over time however, close co-national contact was associated with lower levels of adjustment and higher levels of stress.

In sum, these findings suggest that good (quality) contact is important for promoting cultural adjustment and managing stress, especially during the early stages of a sojourn. Source of close contacts however, does not appear to be crucial in the early stages but becomes more influential over time. While previous research on international students has shown that contact with host nationals promotes cultural adjustment and limits stress (e.g., Kashima \& Loh, 2006), our results indicate that the co-national bubble may have the contrary effect.

\subsection{Intergroup affect}

In accordance with the contact hypothesis (Allport, 1954; Pettigrew \& Tropp, 2006), we predicted that close contact with host nationals would have a positive impact on affect towards host nationals, and possibly towards secondary outgroups. We did indeed find evidence for the former, but not for the latter. Close contact with host nationals was positively associated with affect towards host nationals, but unrelated to affect towards two unrelated outgroups, Dutch and Moroccans. The

\footnotetext{
${ }^{4}$ Bivariate correlations were inspected as a follow-up. Importantly, the relationship between number of host national close contacts and affect towards
} the Dutch did not emerge at the correlational level $(p$ 's $>.20)$. 
present study is not the first to not find evidence of a secondary transfer effect (Stangor et al., 1996). Previous studies that have found this effect however, report that it occurs for groups that are related to the contacted group (Pettigrew, 2009). In the present research this condition was not met. Dutch and Moroccans are salient outgroups in Belgium but do not have an association with participants hosting groups. This may explain the absence of a secondary transfer effect in this study and therefore point to the boundary conditions of the effect.

Regarding co-national contact, we hypothesised that having more co-nationals as close contacts would lead to both ingroup favouritism and secondary outgroup derogation (Tajfel \& Turner, 1986). Evidence was found for the latter, but not for the former. The absence of an increase in positive affect towards the ingroup (ingroup favouritism) may be explained by the context of this study. Sojourning may impact more on perceptions of outgroups rather than the ingroup. This could be explored in future research employing additional measures of intergroup biases. Interestingly, outgroup derogation appeared to occur towards two outgroups unrelated to host nationals but related to the co-national group. It was found that more close contact with co-nationals during the sojourn was related to greater negative affect towards salient Belgian outgroups (Dutch and Moroccans).

Importantly, there was no outgroup derogation effect towards host nationals, for which there could be a number of explanations. First, exchange students are typically motivated to learn about the host culture and generally think and feel positively towards the host society (Richmond, 1993). Close co-national contact would not necessarily alter this. Second, participants may identify with the host society, with it becoming an ingroup. Although this could be easily tested, we did not measure identification over time in this study. A final explanation could be related to cognitive contrast. Extensive contact with co-nationals may have made the Belgian identity more salient. Consequently, outgroups related to this identity may have become activated along with associated cognitions and affect. Because host nationals have no such association with the Belgian ingroup, this effect would be limited to the relevant outgroups (Dutch and Moroccans). It would be interesting to explore these explanations in future research.

\subsection{Sojourn evaluation}

Good overall contact quality was predictive of a more positive evaluation of the sojourn one year later. In addition, sojourners reporting having more close co-national contacts (over host and other internationals), evaluated their sojourn less positively. Typically, one of the main goals of study abroad programmes is to learn from and interact with individuals of different cultural backgrounds. Close contact with host nationals and other internationals would therefore be vital in satisfying this goal.

\subsection{Strengths and limitations}

The present study has a number of strengths. The longitudinal design is particularly powerful. With four distinct measurement waves, participants could be tracked for a long period abroad, while controlling for baseline and measuring the long term influences of close contacts quality and source. In addition, whereas many studies have looked at the effect of contact with one particular group on perceptions of that same group, our design allowed us to examine the effects of contact from two distinct sources, host and co-nationals, on perceptions of several groups. An additional benefit was the nature of the host national group in relation to participants. Most participants had not travelled to the host country before, which allowed us to study perception of a novel and realistic group.

Further, the present research is perhaps unique in examining the effect of close contact on a broad spectrum of outcome variables, all of which are relevant in the context of intercultural contact. Previous research has examined the effect of contact on these outcome variables in isolation, but not together in a single study as we have done here. The research also has some practical implications for the preparation and support of sojourners, be they exchange students, international students or expatriates. Our findings highlight both the significance of host national contact in cultural adjustment and the danger of the co-national bubble.

While this study does have a number of strengths, it is also limited in certain ways. It is conceivable that the findings reported here would generalise to other sojourning groups such as international university students or students on a gap year. ${ }^{5}$ In contrast with international university students however, this particular sample does differ in important ways. While abroad, these students attend a local school and live with a local host family, providing a naturally high level of exposure to host nationals on a daily basis. While there is a clear discrepancy in the availability of host national contacts between students in the study and other types of international students, it is likely that the latter would also benefit from more host national contact and less co-national contact while abroad.

For other relocating samples, such as migrants however, conditions such as length of stay, and motivation, are likely to be very different to those of short term sojourners. Therefore, the results of this study may not generalise to migrant samples, as these key differences are likely to qualify the effect of intercultural contact. For instance, some research has shown that segregation from host nationals may also have positive effects (Postmes \& Branscombe, 2002).

\footnotetext{
${ }^{5}$ A gap year or sabbatical is a period of time that is taken between life stages. Students on a gap year might travel, engage in volunteer work overseas or undertake a working holiday abroad.
} 
Finally, the present study utilised a concise adjustment measure created by the researchers. However, this measure does not distinguish between sociocultural and psychological aspects of cultural adjustment (Ward \& Kennedy, 1996). These separate dimensions have been shown to vary in terms of their development over time and their relationships with other variables (Ward, Okura, Kennedy, \& Kojima, 1998). It is possible, that contact quality and source may have differential effects on these two types of adjustment. Whether this is indeed the case should be explored in future research.

\section{Conclusion}

The present study demonstrates that good quality contact, irrespective of source, has a strong positive impact at the start of a sojourn on stress and cultural adjustment. Over time, too much close contact with co-nationals can hinder cultural adjustment and increase stress, implying that having more close contact with host nationals and perhaps other internationals would allow the sojourner to profit more readily from the novel cultural environment. This is important for continued cultural adjustment, well-being, and positive intergroup relations. In addition, too much close contact with co-nationals may impact negatively on the perception of secondary outgroups. Thus, it seems that travel may not always broaden the mind, especially if one does not choose their international contacts wisely.

\section{Acknowledgements}

The authors wish to thank Mitch Callan, Anne Mees, Tim Rakow, Steven Saeys, Geoff Ward, and AFS Belgium-Flanders for their contributions to the project.

\section{References}

Adelman, M. B. (1988). Cross-cultural adjustment: A theoretical perspective on social support. International Journal of Intercultural Relations, $12,183-205$.

Allport, G. W. (1954). The nature of prejudice. Reading, MA: Addison-Wesley.

Aspeslagh, R., Boen, F., Dekker, H., Linssen, H., Pepermans, R., Vanbeselaere, N., et al. (2000). België en Nederland in beeld: Wat weten, denken en vinden jongeren in België en Nederland van elkaars landen en bevolkingen? Een empirish onderzoek in opdracht van de Belgisch-Nederlandse vereniging. The Netherlands: Nederlands Instituut voor Internationale Betrekkingen.

Berry, J. W. (2006). Stress perspectives on acculturation. In D. L. Sam, \& J. W. Berry (Eds.), The Cambridge handbook of acculturation psychology (pp. 43-57). United Kingdom: Cambridge University Press.

Berry, J. W., Kim, U., Minde, T., \& Mok, D. (1987). Comparative studies of acculturative stress. International Migration Review, 21 , 491 -511.

Billiet, J., \& Swyngedouw, M. (2009). Etnische minderheden en de Vlaamse kiezers: Een analyse op basis van de postelectorale verkiezingsonderzoeken. Belgium: Katholieke Universiteit Leuven, Centrum voor Sociologisch Onderzoek.

Bochner, S. (2006). Sojourners. In D. L. Sam, \& J. W. Berry (Eds.), The Cambridge handbook of acculturation psychology (pp. 181-198). United Kingdom: Cambridge University Press.

Bowman, N. A., \& Griffin, T. M. (2012). Secondary transfer effects of interracial contact: The moderating role of social status. Cultural Diversity and Ethnic Minority Psychology, 18, 35-44.

Brown, L., \& Holloway, I. (2008). The adjustment journey of international postgraduate students at an English university: An ethnographic study. Journal of Research in International Education, 7, 232-249.

Brown, R., \& Hewstone, M. (2005). An integrative theory of intergroup contact. In M. Zanna (Ed.), Advances in experimental social psychology (37) (pp. 255-331). San Diego (CA): Academic Press.

Brown, R., Vivian, J., \& Hewstone, M. (1999). Changing attitudes through intergroup contact: The effects of group membership salience. European Journal of Social Psychology, 29, 741-764.

Cemalcilar, Z., \& Falbo, T. (2008). Longitudinal study of the adaptation of international students in the United States. Journal of Cross-cultural Psychology, 39, $799-804$.

Church, A. T. (1982). Sojourner adjustment. Psychological Bulletin, 91, 540-572.

Cohen, S., Kamarck, T., \& Mermelstein, R. (1983). A global measure of perceived stress. Journal of Health and Social Behavior, 24, 385-396.

Cohen, S., \& Wills, T. A. (1985). Stress, social support, and the buffering hypothesis. Psychological Bulletin, 98, $310-357$.

Dunbar, R. I. M., \& Spoor, M. (1995). Social networks, support cliques and kinship. Social networks, support cliques and kinship. Human Nature, 6, $273-290$.

Fritz, M. V., Chin, D., \& DeMarinis, V. (2008). Stressors, anxiety, acculturation and adjustment among international and North American students. International Journal of Intercultural Relations, 32, 244-259.

Furnham, A., \& Li, Y. H. (1993). The psychological adjustment of the Chinese community in Britain: A study of two generations. British Journal of Psychiatry, $162,109-113$.

Geeraert, N., \& Demoulin, S. (2013). Acculturative stress or resilience? A longitudinal multilevel analysis of sojourners' stress and self-esteem. Journal of Cross-Cultural Psychology, 44, 1239-1260.

Haddock, G., Zanna, M. P., \& Esses, V. M. (1993). Assessing the structure of prejudicial attitudes: The case of attitudes toward homosexuals. Journal of Personality and Social Psychology, 65, 1105-1118.

Hendrickson, B., Rosen, D., \& Aune, R. K. (2011). An analysis of friendship networks, social connectedness, homesickness, and satisfaction levels of international students. International Journal of Intercultural Relations, 35, 281-295.

Hogg, M. A. (2003). Social identity. In M. R. Leary, \& J. P. Tangney (Eds.), Handbook of self and identity (pp. 462-479). New York: Guilford.

Hox, J. (2010). Multilevel analysis: techniques and applications (2nd ed.). New York (NY): Routledge.

Islam, M. R., \& Hewstone, M. (1993). Dimensions of contact as predictors of intergroup anxiety, perceived out-group variability, and out-group attitude: An integrative model. Personality and Social Psychology Bulletin, 19, 700-710.

Kashima, E. S., \& Loh, E. (2006). International students' acculturation: Effects of international, conational, and local ties and need for closure. International Journal of Intercultural Relations, 30, 471-485.

Moscatelli, S., \& Rubini, M. (2011). The impact of group entitativity on linguistic discrimination: Ingroup favoritism and outgroup derogation in the explanation of negative outcome allocations. Social Psychology, 42, 292-299.

Nash, D. (1991). The course of sojourner adaptation: A new test of the U-curve hypothesis. Human Organization, 50, $283-286$.

Neri, F., \& Ville, S. (2008). Social capital renewal and the academic performance of international students in Australia. The Journal of Socio-Economics, 37 , $1515-1538$.

Pettigrew, T. F. (1998). Intergroup contact theory. Annual Review of Psychology, 49, 65-85.

Pettigrew, T. F. (2009). Secondary transfer effect of contact: Do intergroup contact effects spread to noncontacted outgroups? Social Psychology, 40, 55-65. 
Pettigrew, T. F., \& Tropp, L. (2000). Does intergroup contact reduce prejudice? Recent meta-analytic findings. In S. Oskamp (Ed.), Reducing prejudice and discrimination (pp. 93-114). Mahwah, NJ: Lawrence Erlbaum Associates.

Pettigrew, T. F., \& Tropp, L. R. (2006). A meta-analytic test of intergroup contact theory. Journal of Personality and Social Psychology, 90, 751-783.

Postmes, T., \& Branscombe, N. R. (2002). Influence of long-term racial environmental composition on subjective well-being in African Americans. Journal of Personality and Social Psychology, 83, 735-751.

Rasbash, J., Charlton, C., Browne, W. J., Healy, M., \& Cameron, B. (2009). MLwiN Version 2.1. Centre for Multilevel Modelling: University of Bristol.

Richmond, A. H. (1993). Reactive migration: Sociological perspectives on refugee movements. Journal of Refugee Studies, 6, 7-24.

Searle, W., \& Ward, C. (1990). The prediction of psychological and sociocultural adjustment during cross-cultural transitions. International Journal of Intercultural Relations, 14, 449-464.

Smith, R. A., \& Khawaja, N. G. (2011). A review of acculturation experiences of international students. International Journal of Intercultural Relations, 35 , 699-713.

Smolderen, K. G. E., Vingerhoets, A. J. J. M., Croon, M. A., \& Denollet, J. (2007). Personality, psychological stress, and self-reported influenza symptomatology. BMC Public Health, 7, 339.

Stangor, C., Jonas, K., Stroebe, W., \& Hewstone, M. (1996). Influence of student exchange on national stereotypes, attitudes and perceived group variability. European Journal of Social Psychology, 26, 663-675.

Sykes, I. J., \& Eden, D. (1987). Transitional stress, social support and psychological strain. Journal of Occupational Behavior, 6, $293-298$.

Tajfel, H. (1974). Social identity and intergroup behaviour. Social Science Information, 13, 65-93.

Tajfel, H., \& Turner, J. C. (1986). The social identity theory of intergroup behavior. In S. Worchel, \& W. G. Austin (Eds.), Psychology of intergroup relations (2nd ed., 37, pp. 7-24). Chicago: Nelson-Hall.

Tausch, N., Hewstone, M., Kenworthy, J. B., Psaltis, C., Schmid, K., Popan, J. R., et al. (2010). Secondary transfer effects of intergroup contact: Alternative accounts and underlying processes. Journal of Personality and Social Psychology, 99, 282-302.

Turner, R. N., Hewstone, M., \& Voci, A. (2007). Reducing explicit and implicit outgroup prejudice via direct and extended contact: The mediating role of self-disclosure and intergroup anxiety. Journal of Personality and Social Psychology, 93, 369-388.

United Nations. (2009). Trends in international migrant stock: The 2008 revision (United Nations database, POP/DB/MIG/Stock/Rev.2008), data in digital form.

United Nations Educational, Scientific and Cultural Organization. (2013). UNESCO Institute for Statistics [Data file]. Retrieved from http://www.stats.uis.unesco.org/

Wang, K. T., Heppner, P. P., Fu, C.-C., Zhao, R., Li, F., \& Chuang, c-C. (2012). Profiles of acculturative adjustment patterns among Chinese international students. Journal of Counseling Psychology, 59, 424-436.

Ward, C., Bochner, S., \& Furnham, A. (2001). The psychology of culture shock. East-Sussex: Routlegde.

Ward, C., \& Kennedy, A. (1993a). Psychological and socio-cultural adjustment during cross-cultural transitions: A comparison of secondary students overseas and at home. International Journal of Psychology, 28, 129-147.

Ward, C., \& Kennedy, A. (1993b). Where's the culture in cross-cultural transition? Comparative studies of sojourner adjustment. Journal of Cross-cultural Psychology, 24, 221-249.

Ward, C., \& Kennedy, A. (1996). Crossing cultures: The relationship between psychological and socio-cultural dimensions of cross-cultural adjustment. In J. Pandey, D. Sinha, \& D. P. S. Bhawuk (Eds.), Asian contributions to cross-cultural psychology (pp. 289-306). New Delhi: Sage.

Ward, C., Okura, Y., Kennedy, A., \& Kojima, T. (1998). The U-curve on trial: A longitudinal study of psychological and sociological adjustment during cross-cultural transition. International Journal of Intercultural Relations, 22, 277-291.

Woolf, M. (2007). Impossible things before breakfast: Myths in education abroad. Journal of Studies in International Education, 11, 496-509.

Yoon, E., Lee, R. M., \& Goh, M. (2008). Acculturation, social connectedness, and subjective well-being. Cultural Diversity and Ethnic Minority Psychology, 14, $246-255$.

Zhang, J., \& Goodson, P. (2011). Predictors of international students' psychosocial adjustment to life in the United States: A systematic review. International Journal of Intercultural Relations, 35, 139-162.

Zhou, W.-X., Sornette, D., Hill, R. A., \& Dunbar, R. I. M. (2005). Discrete hierarchical organization of social group sizes. Proceedings of the Royal Society B, 272, 439-444. 